\title{
Arte e cultura digital na Educação Infantil: a galáxia na palma da mão
}

\author{
Digital art and culture in early childhood education: \\ the galaxy in the palm of the hand
}

\section{Arte y cultura digital en la educación infantil: la galaxia en la palma de la mano}

Margarete Sacht Góes '

https://orcid.org/0000-0002-7|46-6022

Mariana Sperandio Teixeira²

https://orcid.org/0000-0002-7953-8350

Resumo: $O$ projeto investiga as práticas voltadas para a inserção da Cultura Digital no âmbito da Arte na Educação Infantil, pois de acordo com a Base Nacional Comum Curricular - BNCC (BRASIL, 20I7), a Cultura Digital se destaca a partir das tecnologias digitais de comunicação e informação. Analisa os documentos orientadores sobre o ensino da Arte na Educação Infantil a partir da pesquisa documental, tomando por base os estudos de Le Goff (1996), Pretto e Pinto (2006) e em Pinto, Silva e Anjos (2017), busca subsídios para discutir as novas tecnologias. Realiza um estudo de caso em duas escolas, uma em Vitória-ES e outra em Vila Velha-ES, entrevistando professores, refletindo sobre as práticas voltadas para as novas tecnologias e analisando suas implicações no processo ensino-aprendizagem de Arte, culminando em uma ação pedagógica intitulada "A Galáxia na palma da mão" que envolveu Arte e Tecnologia. Finaliza refletindo sobre como essas práticas contribuem para estimular a aprendizagem das crianças, além de relacioná-las com os documentos oficiais que orientam a Educação Infantil.

Palavras-chave: Arte/Educação. Cultura Digital. Ensino da arte. Infância.

Abstract: The project investigates practices aimed at the insertion of Digital Culture in the field of Art in Early Childhood Education, because according to the Common National Curricular Base - BNCC (BRAZIL, 20I7), Digital Culture stands out from the digital technologies of communication and information. It analyzes the guiding documents on Art teaching in Early Childhood Education from documentary research, based on the studies of Le Goff (1996), Pretto and Pinto (2006) and Pinto, Silva and Anjos (2017), seeking subsidies to discuss new technologies. It carries out a case study in two schools, one in Vitória-ES and the other one in Vila Velha-ES, interviewing teachers, reflecting on practices aimed at new technologies and analyzing their implications in the process of teaching-learning Art, culminating in a pedagogical action entitled "The Galaxy in the palm of the hand"

\footnotetext{
I Doutora em Educação. Professora da Universidade Federal do Espírito Santo - UFES. E-mail: margarete.goes@ufes.br

${ }^{2}$ Graduada em Artes Visuais. Integrante do Grupo de Estudos e Pesquisas em Arte na Educação Infantil - GEPAEl, da Universidade Federal do Espírito Santo - UFES. E-mail: sperandio.mariana@gmail.com
}

Olhar de professor, Ponta Grossa, v. 24, p. I-20, e-17578.064, 202 I.

Disponível em <https://revistas2.uepg.br/index.php/olhardeprofessor> 
that involved Art and Technology. It concludes by reflecting on how these practices contribute to stimulate children's learning, as well as relate them to the official documents that guide Early Childhood Education.

Keywords: Art/Education. Digital Culture. Art teaching. Childhood.

Resumen: El proyecto estudia las practicas dirigidas a la inserción de la Cultura Digital en el campo del Arte en la Educación Infantil, debido a que según la Base Curricular Común Nacional - BNCC (BRASIL,20I7), la Cultura Digital sobresale de las tecnologías digitales de comunicación e información. Esta analiza los documentos directores sobre la enseñanza del Arte en la Educación Infantil a partir de la investigación documental, tomando como base los estudios de Le Goff (1996), Pretto y Pinto (2006) y Pinto, Silva e Anjos (20l7), buscando contribuciones para discutir nuevas tecnologías. Así mismo, se realiza estudios de caso en dos escuelas, una en Vitória-ES y la otra en Vila Velha-ES, entrevistando a maestros, reflexionando sobre las practicas dirigidas a las nuevas tecnologías y analizando sus alcances en el proceso de enseñanza-aprendizaje del Arte, culminando de esta manera en una acción pedagógica denominada "La Galaxia en la palma de la mano" que comprende Arte y Tecnología. En conclusión, reflexiona sobre como estas prácticas colaboran a estimular el aprendizaje de los niños, en adición de conectarlos con los documentos oficiales que orientan la Educación Infantil.

Palabras-clave: Arte/Educación. Cultura Digital. Enseñanza de arte. Infancia.

\section{Introdução}

Por compreendermos que estamos em um mundo em que cada vez mais a dependência da tecnologia é perceptível e indispensável, e na Arte, isso não é diferente, objetivamos com este artigo investigar as práticas voltadas para a inserção da Cultura Digital ${ }^{3}$ no âmbito da Arte para/na Educação Infantil.

Desde a "[...] década de 1960 quando alguns artistas contemporâneos passaram a abandonar os suportes tradicionais da arte visual e perceber potencial criativo nos suportes técnicos" (LOUISE, 2020, p. I), vemos exemplos de manifestações artísticas que envolvem Arte e Tecnologia. Ademais, nesses tempos de isolamento social, a rede de internet se tornou imprescindível para 0 desenvolvimento e divulgação das propostas online para apresentar exposições, trabalhos de artistas e Instituições Culturais que tiveram seus eventos adiados e/ou cancelados.

No entanto, consoante a Pimentel (2003), a preocupação com o meio educacional é recente, já que, normalmente, as novas tecnologias não são/estão voltadas para a escola, haja vista o desafio que está sendo para as/os professoras/es planejarem e ministrarem aulas de forma remota durante 0 isolamento social devido a Pandemia Covid- 19. Dessa maneira, torna-se um ponto substancial se pensar nessa inserção, principalmente porque a Base Nacional Comum Curricular - BNCC (BRASIL, 20I7) já acenava para a urgência de mudança em relação às novas tecnologias nas escolas da Educação Básica.

A BNCC, aprovada em dezembro de 2017, ao contemplar a Educação Básica (Educação Infantil, Ensino Fundamental e Ensino Médio), aborda, dentre suas competências gerais, o tema Cultura Digital,

\footnotetext{
${ }^{3}$ Cultura digital aqui compreendida em relação à forma como nos relacionamos com as tecnologias de informação, indicando "[...] intrinsecamente um processo crescente de reorganização das relações sociais mediadas pelas tecnologias digitais, afetando em maior ou menor escala todos os aspectos da ação humana" (PRETTO; ASSIS, 2008, p. 78).
} 
conceito que diz respeito às tecnologias digitais de comunicação e informação, segundo as quais é preciso:

Compreender, utilizar e criar tecnologias digitais de informação e comunicação de forma crítica, significativa, reflexiva e ética nas diversas práticas sociais (incluindo as escolares) para se comunicar, acessar e disseminar informações, produzir conhecimentos, resolver problemas e exercer protagonismo e autoria na vida pessoal e coletiva (BRASIL, 2017, p. 9).

Preocupar-se com ensino das novas tecnologias é necessário, pois mesmo quem ainda não tinha a intenção de usá-las em suas aulas e atividades, com a pandemia do Corona Vírus, viu essa demanda tornar-se algo que está posto e que circula pela vida e em nosso entorno.

A partir dessa perspectiva, podemos pensar que o campo da Arte, conforme já acenamos, desde a década de 1960, conecta-se, de forma muito direta, com os recursos tecnológicos e está aberto para contribuir, ou melhor, a dialogar intimamente com ações que visam à produção de conhecimentos de forma crítica e lúdica.

Em busca de subsidiar materiais para essas demandas já normatizadas pela BNCC e, agora, implicadas pelo contexto dessa crise sanitária mundial, destacamos a urgência de desenvolver um estudo sobre a Arte e a Cultura Digital na Educação Infantil.

Nesse sentido, com o objetivo de ampliar essa discussão, organizamos esse texto em quatro partes. Após esta Introdução, no primeiro tópico, refletiremos sobre "O que os documentos oficiais dizem sobre Arte e Tecnologia”, fundamentadas teoricamente em Le Goff (1996), Bakhtin (2003), Pretto e Pinto (2006), Pinto, Silva e Anjos (2017) e Furtado (2019).

No segundo tópico “Arte e Tecnologia nas redes municipais de Vitória-ES e Vila Velha - ES”, trazemos o estudo de caso realizado em duas escolas de Educação infantil: uma localizada no município de Vitória, por ter professor/a dinamizador/a licenciado/a em Artes Visuais, e outra, no município de Vila Velha, cujas atividades de Arte são ministradas pelo/a professor/a licenciado/a em Pedagogia, dedicando-nos à análise das narrativas das professoras a partir de questionários e entrevistas realizadas e fundamentadas na perspectiva enunciativo-discursiva bakhtiniana.

No terceiro tópico, trazemos nossa proposta de ação pedagógica denominada "A Galáxia na palma da mão". Essa ação pedagógica se constituiu com o objetivo de contribuir para a formação de educadores/as da Educação Infantil, tanto professoras/es licenciadas/os em Artes Visuais quanto em Pedagogia, e, nesse sentido, salientamos a importância de haver formações continuadas, reforçando temáticas que, como essa, estão sendo acrescentadas agora aos currículos das Universidades brasileiras, entretanto, de forma, inigualável e urgente, integraram a realidade das/os professoras/es, crianças, de suas famílias e das escolas.

Olhar de professor, Ponta Grossa, v. 24, p. 1-20, e-17578.064, 2021. 
Arte e cultura digital na Educação Infantil: a galáxia na palma da mão

Finalmente, na última parte, tecemos nossas considerações, nela refletimos sobre "ações educativas possíveis", visto que a execução da atividade "A Galáxia na palma da mão" foi impedida de ser desenvolvida com as crianças e professoras dessas duas instituições devido a Pandemia Covid-19, que implicou no fechamento das escolas com o intuito de conter o avanço da doença.

\section{O que os documentos oficiais dizem sobre Arte e Tecnologia}

Segundo Le Goff (1996), os documentos são o testemunho e o ensinamento, devendo-se, portanto, analisá-los em primeira instância, revelando seu conteúdo e os "mistérios" que os cercam, os quais têm o peso de monumento. $O$ autor complementa, inferindo que são resultados de esforços da sociedade em registrar os acontecimentos a fim de perpetuar a história, e que a leitura deles deve ser feita com "os pés no chão", não ir além dos fatos, ficando o mais próximo do excerto.

Aproximando-nos dessa perspectiva teórica, trazemos para o diálogo Bakhtin (2003). Ele nos orienta que os documentos devem ser compreendidos como textos, enunciados produzidos na interação verbal entre os sujeitos. Para o autor, "[...] independentemente de quais sejam os objetivos de uma pesquisa, só o texto pode ser o ponto de partida" (BAKHTIN, 2003, p. 308).

Consideramos que o texto será o nosso ponto de partida e de chegada, tentando compreender sempre os sentidos produzidos a partir dos diferentes e diversos contextos.

Refletindo, então, sobre a homologação do documento Base Nacional Comum Curricular em dezembro de 2017, surge a preocupação se são oferecidos conteúdos ligados à Tecnologia e às Novas Mídias dentro da Educação Infantil, uma vez que esse conteúdo é citado entre as competências do documento, e se isso, de fato, contribui positivamente para a aprendizagem, a cognição e a fruição das crianças pequenas, quando esse conteúdo dialoga com o campo do ensino da Arte.

Nesse contexto, surge a preocupação de compreender se os/as professores/as atuantes na Educação Infantil, em sua formação - seja ela inicial ou continuada - foram apresentadas/os a noções sobre as novas tecnologias imbricadas em relação ao ensino da Arte. De acordo com Pretto e Pinto (2006):

\footnotetext{
Tais sistemas (de comunicação) constituem-se em elementos estruturantes (Pretto, 1996) de uma nova forma de ser, pensar e viver. A dimensão estruturante das tecnologias da informação, que Pierre Levy (1993) denomina de tecnologias coletivas ou tecnologias da inteligência, tem mexido muito com todos nós, especialmente os educadores. Isso porque essas tecnologias, antes entendidas como meras extensões dos sentidos do homem, hoje são compreendidas como algo muito mais profundo, que interfere com o próprio sentido da existência humana (PRETTO; PINTO, 2006, p. 22).
}

Consoante à afirmação acima de que as tecnologias "[...] hoje são compreendidas como algo muito mais profundo, que interfere com o próprio sentido da existência humana” (PRETTO; PINTO, 
2006, p. 22), trazemos para o diálogo Furtado (2019), quando reflete sobre o perfil das crianças contemporâneas, ou seja, da Geração Alpha. A autora infere que "[...] a chamada Geração Alpha é a primeira geração nascida no conjunto da tecnologia digital, o que, em termos cronológicos, esbarra em meados dos anos 2010" (FURTADO, 2019, p. 423).

Nessa perspectiva, não podemos pensar em proposições educativas sem levar em consideração as crianças que, mesmo em contextos socioculturais, geográficos e econômicos diversos, já nasceram em um mundo digital e chegam "[...] às instituições educacionais com um desempenho instrumental elevado das tecnologias, para uso multifuncional, com destaque para a interação, comunicação e produção síncrona" (FURTADO, 2019, p. 4I8).

Portanto, ao dialogarmos com os documentos oficiais, precisamos levar em consideração não somente a formação dos professores ou as condições estruturais das escolas em relação às novas tecnologias, mas, principalmente, os sujeitos com e para os quais faremos nossas proposições.

Como ressaltamos, ao analisarmos os documentos, direcionamos nossa pesquisa para práticas que envolvam o uso das tecnologias na Arte. Aliar uma à outra nas propostas pedagógicas é interessante, já que juntas se tornam um caminho que potencializará a apropriação dos aspectos históricos, artísticos e culturais das crianças, considerando que isso será feito a partir de uma abordagem próxima ao que as crianças já estão acostumadas, valorizando a aproximação que elas têm com os meios tecnológicos e com as mídias digitais.

Segundo Barbosa (2014):

No contexto contemporâneo, as crianças estão diante de uma infinidade de informações e recursos tecnológicos que as possibilitam desenvolver-se de forma autônoma e participativa. $\mathrm{Na}$ escola, trazem uma bagagem de conhecimentos prévios que devem ser considerados, são os nativos digitais, por estarem diante de um ambiente no qual as mídias estão presentes na vivência em sociedade (BARBOSA et al., 2014, p. 2889).

Para dar conta desses "nativos digitais", que já nasceram imersos nos ambientes em que as "mídias estão presentes na vivência em sociedade", além da Base Nacional Comum Curricular (BRASIL, 2017), o Município de Vitória criou as Diretrizes Curriculares da Educação Infantil Temas Infantis de Vitória (TIVs, 2017), que apontam para uma articulação das novas tecnologias com as diferentes linguagens artísticas. O documento tem como referência a pesquisadora Lúcia Reilly (2004), e nele a autora cita Lucia Santaella:

O metabolismo das linguagens, dos processos e sistemas sígnicos, tais como a escrita, desenho, música, cinema, televisão, rádio, jornal, teatro, pintura, computação gráfica, etc, assemelha-se aos dos seres vivos. Tanto como quaisquer organismos vigentes, as linguagens estão em permanente crescimento e mutação. Os parentescos, trocas e mutações, migrações e intercursos entre as linguagens não são menos densas e 
complexas do que os processos que regem a demografia humana. Enfim, o mundo das linguagens é tão movente e volátil quanto o mundo dos seres vivos. Esta volatilidade não costuma ser levada em conta, nem mesmo percebida, porque, infelizmente, nos currículos escolares, as linguagens são colocadas em campos estanques, rígidas ou asceticamente separadas: a literatura e as formas narrativas em um setor, a arte em outro, o cinema de um lado, a fotografia do outro, a televisão e o vídeo em outra área, a música em outra e etc. Entretanto, é só nos currículos escolares é que elas estão separadas com nitidez. Na vida elas se misturam; a promiscuidade entre as linguagens e os signos são regras (SANTAELLA apud REILY, 2004, p. |80-18I).

Ao analisarmos o documento bem como os autores que o fundamentam teoricamente, percebemos que a citação utilizada, mesmo sendo uma referência do ano de 2004 , tem um teor extremamente atual, quando traz essa articulação com as diferentes linguagens, pois se refere às linguagens Arte e Tecnologia, a exemplo do cinema, da fotografia e do vídeo, além dos inúmeros aplicativos - existentes nos aparelhos celulares, tablets e computadores - que permitem diversas possibilidades para trabalhar essas duas linguagens.

Muller (20I5), em sua pesquisa de mestrado com crianças de 5 e 6 anos, observou que:

Durante 8 meses estivemos em contato com a instituição para a realização da pesquisa que contou com levantamento dos usos que as crianças faziam das tecnologias; manifestações por meio de registro fotográfico e fílmico; brincadeiras com gravação das vozes em áudio; descoberta de alguns truques de "efeitos especiais" com audiovisual; escrita de história, representação e registro a partir de um making-of dos bastidores da peça teatral criada pelo grupo; socialização das preferências dos jogos; relatos de experiência com as tecnologias móveis; discussão sobre seus consumos midiáticos, entre outros (MULLER, 20I5, p. 7).

Essas práticas digitais que, segundo Borges (2019, p.I), podem ser definidas como “[...] conjunto de práticas, costumes e formas de interação social as quais são realizadas a partir dos recursos da tecnologia digital, como a internet e as TICs - Tecnologias de Informação e Comunicação”.

O outro documento que destacamos é a Proposta Curricular da Educação Infantil do município de Vila Velha - Caderno I (20I2), que trata dos eixos das atividades educativas na Educação Infantil.

O documento discorre sobre o ensino das Artes Visuais e, assim como no documento do município de Vitória, destaca o uso das linguagens, dentre elas, a do cinema, a da videoarte e a da fotografia. Para Pereira e Lopes (2005), a partir dessas linguagens e,

[...] com o uso das Tecnologias Digitais da Informação e Comunicação, a escola estará formando 'indivíduos mais criativos que estarão adquirindo novos conhecimentos e integrando-se com um novo modo de aprender e de interagir com a sociedade'. A partir desse princípio, o professor precisa propor atividades pedagógicas que possibilitem aprendizagens significativas, contribuindo para $\circ$ processo de desenvolvimento dos alunos de maneira autônoma e participativa, através de situações e trabalhos de troca de saberes (PEREIRA; LOPES, 2005 apud BARBOSA et al., 20I4, p. 2890). 
Não há dúvida de que as novas tecnologias de comunicação e informação trouxeram mudanças consideráveis e positivas para a educação. No entanto, é necessário pensar esses meios tecnológicos a partir da criança, como um sujeito de direitos, que tem potencial criativo, imagético, produtor e reflexivo, e, assim, de fato, promover aprendizagens significativas e, principalmente, acessíveis a todas as crianças.

\section{Arte e Tecnologia nas redes municipais de Vitória-ES e Vila Velha-ES}

Dando seguimento às nossas proposições, fizemos um estudo de caso em duas escolas de Educação infantil: uma localizada no município de Vitória-ES, por ter professor/a dinamizador/a licenciado/a em Artes Visuais, e outra, no município de Vila Velha-ES, cujas atividades de Arte são ministradas pelo/a professor/a licenciado/a em Pedagogia.

Escolhemos esse tipo de pesquisa qualitativa, pois compreendemos a necessidade de irmos a campo observar as práticas dos/as professores/as, dialogar com eles/as, escutar suas narrativas e, assim, produzir dados para nossas análises.

Sobre o estudo de caso, Souza (2014) pontua que:

[...] o estudo de caso destina-se a analisar em profundidade um determinado caso. Ele pode estar localizado numa sala de aula; numa escola. Um sujeito pode constituir um caso; uma escola pode também constituir um caso. O que precisa ficar claro é que o estudo de caso é assim denominado quando, após um amplo levantamento de dados, constata-se que num determinado lugar há uma particularidade em relação a outros lugares (SOUZA, 20I4, p. 76).

Nesse contexto, o estudo de caso é relevante para que possamos ter contato com o que já é feito nos espaços da Educação Infantil pelos/as professores/as e analisarmos o processo de ensinoaprendizagem através das práticas voltadas para a Cultura Digital no âmbito artístico-cultural, refletindo acerca de sua viabilidade ao ser desenvolvida com crianças pequenas e examinando sua contribuição para a aprendizagem delas.

Deve ser reforçada a importância dessas investigações aprofundadas de determinadas situações que, embora limitadas, expandem significativamente o espaço para discussão e aperfeiçoamento da capacidade de ensino aprendizagem.

A fim de realizar a análise comparativa das práticas das escolas de Vitória e de Vila Velha e com o objetivo de que as equipes responsáveis nos orientassem sobre quais escolas seriam mais apropriadas para a pesquisa e autorizassem sua realização, entramos em contato com as Secretarias de Educação dessas duas cidades. Dessa forma, foi realizado o primeiro contato presencial com esses profissionais (pedagogos/as e professores/as) nas escolas e, posteriormente, por meio de questionários. Ficou 
Arte e cultura digital na Educação Infantil: a galáxia na palma da mão

acordado com a diretora de uma delas que iríamos fazer a entrevista com a Prof. I no intervalo dos turnos, já que se tratava de uma escola de período integral.

Assim, na escola de Educação Infantil do município de Vitória, fizemos a entrevista presencial com a professora de Arte (Prof. I), formada em Artes Visuais no ano de 2005 e que atuava naquele Centro Municipal de Educação Infantil - CMEl desde 2006.

Ainda em relação ao município de Vitória, por meio de um questionário enviado por e-mail, obtivemos as respostas da Pedagoga (Prof. 2), que é formada em Pedagogia e especializada em Educação, que exercia a função de gestora em CMEl há 10 anos e que também já exerceu essa função nos demais segmentos da Educação Básica.

No município de Vila Velha, o contato foi direto com a Coordenadora Pedagógica e a Pedagoga, que são gestoras da Unidade Municipal de Educação Infantil - UMEl. Explicamos a proposta do Projeto e elas sugeriram que se fizessem as entrevistas com uma Professora Pedagoga de cada grupo (3, 4 e 5 anos) e que se responsabilizariam por contatar quem teria interesse em participar da entrevista, recolher as perguntas e depois as repassar para nós. Nesse sentido, tivemos contato com as Professoras (Prof. 3, Prof. 4 e Prof. 5) de forma indireta, formadas em Pedagogia, sendo as professoras 3 e 4 são pós-graduadas. Todas atuavam há mais de uma década e meia na educação, uma delas há 25 anos.

O questionário, além de se constituir como um primeiro contato, teve a função de mapear o conhecimento, o interesse e a aplicação das tecnologias nas aulas destinadas à Educação Infantil, com destaque no campo de experiências, traços, sons, cores e formas. Nessa perspectiva, ele se desenvolveu a partir de cinco perguntas básicas, apresentadas a seguir.

A primeira pergunta solicitava ao professor que relatasse se tinha interesse de trabalhar as novas tecnologias na sala de atividades e se acreditava que esse tipo de proposição era relevante para a formação das crianças. Para ela, tivemos quatro respostas assertivas e uma dissonante. Observamos em nossa pesquisa, que as respostas dadas sobre a temática (novas tecnologias) estavam diretamente ligadas aos professores mais jovens.

Prof. I: Não tenho muita habilidade a respeito. Em algumas ocasiões trabalhei com fotografia.

Prof. 2: Sim, tenho interesse por crer que a convivência com as novas tecnologias favorecerá a aquisição de novos conhecimentos pra esta faixa etária.

Prof. 3: Sim, é bem relevante, pois a tecnologia chega cada vez mais cedo no dia a dia dos nossos alunos.

Prof. 4: Tenho interesse sim, mesmo porque as crianças estão crescendo no meio tecnológico.

Prof. 5: Sim. É um recurso bem atrativo para as crianças.

Quando fizemos essa pergunta à Prof.I, ela afirmou desconhecer o assunto, assim, explicamos o que eram as novas tecnologias, as tecnologias contemporâneas e os novos meios ou ainda tecnologias 
digitais. Exemplificamos que o vídeo, a fotografia, o uso de dispositivos portáteis - a exemplo dos smartphones e tablets - e as tecnologias digitais - tais como QR-Code, Realidade Virtual, Realidade Aumentada e Geolocalização - são considerados instrumentos didático-pedagógicos, quando inseridos nos planejamentos e nas ações pedagógicas.

Nesse sentido, a Prof. I revelou trabalhar com fotografia, porém, o trabalho com fotografia que ela relatou realizar era semelhante a um ensaio fotográfico, pois não trazia o conceito do que é a fotografia, narrando sua história e demonstrando seu uso às crianças.

Assim como a Prof. I, há muitos professores que ainda não compreendem o conceito, não o aplicam adequadamente ou não conseguem, até mesmo, realizar uma transposição didática quando se trata de novas tecnologias. Alguns exemplos relatados consideram que o fato de utilizar um filme no projetor ou televisão é trabalhar com as novas tecnologias.

Coadunamos com Pimentel (2003), quando ela infere que somente deixando a criança na frente da tela, sem nenhuma mediação do professor, não acontece a aprendizagem. Para que ela ocorra, é necessária uma preparação do professor com um planejamento intencional para estimular na criança, além de outras coisas, o pensamento crítico.

As professoras são quase unânimes em dizer que têm interesse em trabalhar com as novas tecnologias e que pensam ser um recurso relevante para a formação das crianças, pela riqueza de possibilidades e atrativos que oferecem, pois elas têm entrado em contato com essas tecnologias cada vez mais cedo.

Nesse sentido, é importante, segundo Libâneo (2006), que haja uma

[...] formação geral e capacitação tecnológica para que os trabalhadores possam exercer mais controle sobre suas condições de trabalho, de modo a não buscar competência apenas em tarefas fixas e previsíveis, mas compreender a totalidade do processo de produção; qualificação mais elevada e de melhor qualidade, de caráter geral do trabalhador, inclusive como condição para quebrar a rigidez da tecnologia (LIBÂNEO, 2006, p. 22).

A segunda pergunta realizada fazia uma abordagem sobre quais os recursos que a escola tinha disponíveis em termos de novas tecnologias/mídias digitais para subsidiar o planejamento dos/as professores/as.

Prof. I: Temos uma câmera fotográfica semiprofissional. Não temos rede de WiFi.

Prof. 2: Os recursos disponíveis são computadores com acesso à internet, impressoras, datashow, lousa digital, massa de modelar, etc.

Prof. 3: Computador com internet.

Prof. 4: Computador com internet, televisão, rádio, DVD e datashow.

Prof. 5: Temos WiFi; notebook; datashow. Seria interessante uma sala de informática para enriquecer nosso trabalho. 
Arte e cultura digital na Educação Infantil: a galáxia na palma da mão

Todas as entrevistadas relataram que as escolas dispõem de alguns recursos digitais, no entanto, são subutilizados.

No caso da Prof. I, há uma câmera fotográfica à disposição, mas que é utilizada somente como meio de registro, ao invés de potencializar as aulas de Arte com o estudo de fotografia, de vídeo, de cinema ou ainda de animação, por exemplo. A Prof. 2, como gestora, aponta que a equipe de professores/as com que trabalha utiliza pouco as ferramentas digitais, havendo resistências por meio deles/as. As professoras das UMEl de Vila Velha (Prof. 3, 4 e 5) revelam utilizar os computadores somente como ferramenta de pesquisas para seus planos de aula.

No entanto, a Prof. 5 sugere que haja um laboratório de informática destinado para o uso das crianças, a fim de estimular a pesquisa e de utilizar jogos pedagógicos, o que poderia ser interessante para as crianças que estão passando pelo processo de alfabetização.

Com a finalidade de se pensar em usos mais significativos das tecnologias contemporâneas em diálogo com a Arte na Educação Infantil, é necessário disponibilizar formações destinadas aos professores/as atuantes, ensinando-lhes a utilizá-las, pois, segundo Evangelista (20II, p. 3) "[...] não adianta a tecnologia oferecer diversos recursos se os professores/as não estiverem devidamente capacitados para lidar com essa ferramenta tecnológica". Dessa forma, há a necessidade de o/a educador/a conhecê-las bem e saber seus usos para, assim, estabelecer um diálogo com o ensino da Arte, outro campo que também carece de formação profissional, e, então, de uma mudança no processo ensino-aprendizagem na Educação Infantil.

A terceira pergunta foi direcionada para sabermos se as respectivas secretarias de ensino ofereciam formação sobre as novas tecnologias/mídias digitais, se as professoras já haviam participado dessas formações e, se sim, quais os assuntos abordados nelas. De acordo com as respostas, a seguir apresentadas, inferimos que formações sobre essa temática ainda são raras para as/os professoras/es da rede municipal.

Prof. I: É um desejo da escola, a Diretora tem fomentado uma formação a respeito. Prof. 2: Ainda não recebi formação na área de novas tecnologias.

Prof. 3: SEMED não dá formação sobre novas tecnologias/mídias digitais.

Prof. 4: A prefeitura oferece curso em plataforma digital. Comecei a fazer, mas desisti, pois não consegui acompanhar. Prefiro aulas presenciais.

Prof. 5: Não.

Ressaltamos, então, a premência das formações sobre as novas tecnologias/mídias digitais para uso na educação, todavia, não têm acontecido muitas iniciativas a esse respeito e, de acordo com o enunciado da Prof. 4, muitas vezes, é o próprio profissional que não tem interesse ou disponibilidade em realizá-las. Nesse sentido, torna-se necessário que os/as próprios/as professores/as busquem meios de suprir essa carência, tornando a internet um possível aliado para essa demanda já existente, haja 
vista que "[...] podemos achar praticamente tudo e qualquer coisa na internet (ou, senão tudo de fato, com certeza as referências para tudo)" (LÉVY, 1999, p. 85), encontrando-se também nela vários artigos relacionados ao uso dessas ferramentas para serem utilizadas no ambiente educacional.

Importante destacar que, no contexto da pandemia COVID 19, as redes sociais, por meio de lives e webinários, tornaram-se, além de espaço de acesso a informações, lócus de formação continuada, de estudo, de aprendizagem, de compartilhamento de ideias e de trocas de experiências.

A quarta pergunta trazia uma questão mais pessoal ao indagar se as professoras gostavam ou tinham interesse em ler sobre essas temáticas para se informar e se atualizar, e sugeria que exemplificassem o que liam, quais sites, revistas, blogs ou outros meios digitais.

Prof. I: Não.

Prof. 2: Leio relativamente pouco sobre o assunto, mas acesso site como https://tecnologia.educacional.com.br/

Prof. 3: Não, sites de educação.

Prof. 4: Sim. Alguns blogs sobre educação. Visito sites que aparecem em alguns grupos de facebook.

Prof. 5: Uso o Google; YouTube; livros paradidáticos.

Apesar da maioria das entrevistadas mostrarem interesse em usar os meios digitais como recursos didáticos/pedagógicos, as respostas mostraram também que a maioria não busca se aperfeiçoar no assunto.

Reiteramos a afirmação de Libâneo (2006), ao inferir que as novas exigências educacionais pedem um/a professor/a capaz de ajustar sua didática à realidade da sociedade, o que implica no "[...] domínio da linguagem informacional e dos meios de informação, habilidade de articular as aulas com as mídias e multimídias" (LIBÂNEO, 2006, p. 28).

A última pergunta estava relacionada ao planejamento e em como as/os professoras/es incluíam as atividades que envolviam as novas tecnologias.

Prof. I: Somente fotografia como ensaio fotográfico.

Prof. 2: Existe grande resistência por parte dos professores na Educação Infantil, que aceitam trabalhar em atividades com o uso de vídeo.

Prof. 3: Uso tecnologia para pesquisar atividades e ideias para projetos.

Prof. 4: Sim. Filmes, músicas, pesquisas.

Prof. 5: Sim.

Interessante notar que, em suas respostas, as professoras demonstram interesse em utilizar as novas tecnologias nas atividades com as crianças como recursos para planejamento das aulas por meio do uso de equipamentos como televisão e datashow, mas não, necessariamente, para aplicá-los em ações pedagógicas.

Fundamentamo-nos em Pinto, Silva e Anjos (2017) para ressaltar que: 
Os professores, os alunos e a escola devem adquirir, no contexto da sociedade tecnológica, novas competências para conseguir sucesso nas relações que estabelecem. Entre as qualidades necessárias na escola da sociedade tecnológicas destacamos a autonomia, o trabalho colaborativo, a reflexão e o domínio da linguagem digital. Daí a necessidade de inserir nos cursos de formação de professores disciplinas voltadas para a instrumentalização dos alunos para o uso das NTICs (Novas Tecnologias da Informação e Comunicação) como recurso didáticopedagógico. Mais que instrumentalizar tecnicamente os futuros professores, consideramos importante dialogar criticamente sobre as realidades e possibilidades do uso das novas tecnologias na educação (PINTO; SILVA; ANJOS, 2017, p. 59).

Reafirmando o que foi dito pelos autores, é interessante pensar em uma formação para os/as professores/as sobre os usos das tecnologias e suas possibilidades didático-pedagógicas a fim de enriquecer o ensino-aprendizagem com as crianças.

Compreendemos que ouvir o que as/os professoras/es têm a nos dizer sobre o que vivenciam em suas salas de atividades, seus desafios e conquistas é de fundamental importância quando pensamos em uma pesquisa pautada no diálogo, no respeito e na ausculta (BAKHTIN, 2003), portanto, deixamos um espaço aberto para as narrativas das professoras.

Prof. I: Achei válida a proposta, pois nunca tinha imaginado inserir isso no plano de aula.

Prof. 2: É importante trazer o conhecimento da utilização de novas tecnologias principalmente no universo da Educação infantil; para qualificar as aprendizagens e aumentar as possibilidades de conhecimento e visão do mundo.

Prof. 3: A Secretaria de Educação poderia começar formações envolvendo o tema. Prof. 4: Não se manifestou.

Prof. 5: O que nos falta na Educação Infantil é um laboratório de informática, onde poderíamos planejar aulas com jogos pedagógicos e incentivar a inicialização de pesquisa.

De acordo com as respostas dadas, observamos que as professoras são a favor do uso das novas tecnologias para a Educação Infantil e sugerem que sejam oferecidas formações para isso. Ainda há dúvidas sobre o emprego de recursos tecnológicos como fonte de estudo, principalmente, para as crianças pequenas.

Dessa maneira, nosso objetivo se estende em uma proposta de intervenção pedagógica, envolvendo Arte e Tecnologia, para contribuir com esse entendimento ao propor ações educativas que auxiliarão as crianças em seu processo de interação com as novas tecnologias e na utilização delas para fins de obtenção de conhecimento, ainda que, nesse caso, seja especificamente para a área das Artes Visuais, mas criando uma base potente em torno desses novos meios. Certamente, compreendemos que esses dispositivos contribuirão, também, como subsídios, para as práticas pedagógicas dos educadores/as inseridos/as na Educação Infantil.

De acordo com Callegaro (2003), é necessário um cuidado especial ao inserirmos o uso de softwares para não cairmos no "tecnicismo" (prática pela prática), sendo o ideal usá-lo como um meio 
de suporte para o desenvolvimento de uma poética de trabalho artístico, contando que $\circ$ mais importante do ensino da Arte e Tecnologia é a implicação social e estética envolvida, e não a ferramenta em si do computador e seus programas, valorizando, assim, uma discussão a respeito e incentivando um desenvolvimento de pensamento crítico.

Nessa direção, pensamos em criar um ambiente favorável ao desenvolvimento e à aprendizagem das crianças por meio das análises críticas dos objetos artísticos com os quais elas terão contato durante sua trajetória de vida, utilizando meios tecnológicos disponíveis para agregarmos valor ao trabalho, levando em consideração a idade das crianças, seus conhecimentos prévios e seus contextos socioculturais, econômicos e geográficos e propondo, para o ensino da Arte na/para a Educação Infantil, a produção de outros saberes-fazeres a partir do viés dialógico com a Arte Contemporânea que, nesse caso, inter-relaciona-se com a Cultura Digital.

\section{A Galáxia na palma da mão}

Tenho um universo inteiro dentro de mim que costumo chamar de casa e posso carregar pra qualquer canto do mundo (OÁ GALERIA ARTE CONTEMPORÂNEA, 2019).

Com base no objetivo dessa pesquisa, que é investigar as práticas voltadas para a inserção da Cultura Digital no âmbito da Arte para/na Educação Infantil, desenvolvemos uma proposta de ação pedagógica possível de ser experienciada nesse segmento ao explorarmos os campos de experiências que envolvem a Arte e a Tecnologia.

O projeto apresenta como tema “A Galáxia na palma da mão”, no qual se propõe realizar uma experiência de Realidade Aumentada (R.A.) através do uso de aplicativo "Merge Explorer", compatível com smartphones e tablets, com o objetivo de vivenciar com as crianças pequenas a percepção do espaço, envolvendo a Arte e a Tecnologia.

A Realidade Aumentada é caracterizada pela interação entre ambientes virtuais e o mundo físico, pois ela

[...] combina um código QR e um programa de computador. Com os códigos bidimensionais é possível projetar objetos virtuais em uma imagem do mundo real de forma a oferecer mais informações, expandir as fronteiras da interatividade, bem como possibilitar o uso de novas tecnologias e tornar as atuais mais precisas (ANDRION, 2019, p.I).

Dessa forma, propomos a utilização do Merge Cube, um cubo holográfico desenvolvido para se trabalhar com Realidade Aumentada (RA), que permite a projeção de objetos em 3D e a interação a partir do uso de aplicativos. 
Para a realização da projeção, sugerimos o aplicativo "Merge Explorer", que foi projetado especialmente para o uso educacional, que abrange diversos conteúdos, grande parte gratuitos, e que não precisa de internet para funcionar.

A motivação de trabalhar com o Merge Cube (Figura I) veio a partir de uma experiência vivenciada no final de 2019 no Centro de Educação Infantil Criarte, localizado dentro do Campus da Universidade Federal do Espírito Santo em Goiabeiras (UFES). Nele acompanhamos um grupo denominado Grupo 3, formado por crianças de três anos de idade.

Como as crianças estavam aprendendo sobre o Sistema Solar, experimentamos mostrar a elas o cubo holográfico interagindo com o aplicativo "Merge Explorer", elas responderam de forma bem positiva, mostrando-se muito interessadas.

Figura I: Interação com Merge Cube e aplicativo Merge Explorer - Galactic Explorer

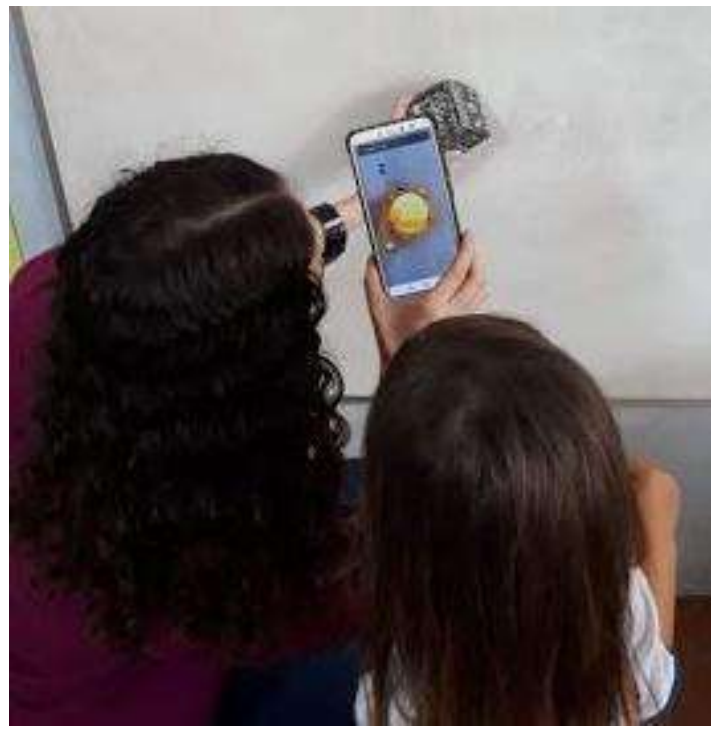

Fonte: acervo das autoras, 2019.

O cubo pode ser adquirido por meio de compra em lojas virtuais, mas o valor dele no Brasil ainda é caro. Entretanto, uma ótima opção é construir, através da versão Merge Paper Cube, ${ }^{4}$ uma versão para imprimir criada pela própria empresa Merge Edu (Figura 2), caso tenha intenção de testar o produto antes de realizar a compra.

\footnotetext{
${ }^{4}$ Link para baixar a versão Merge Paper Cube https://mergeedu.com/download/file.php?f=paper-merge-cube.pdf 
Figura 2: Merge Paper Cube ${ }^{5}$

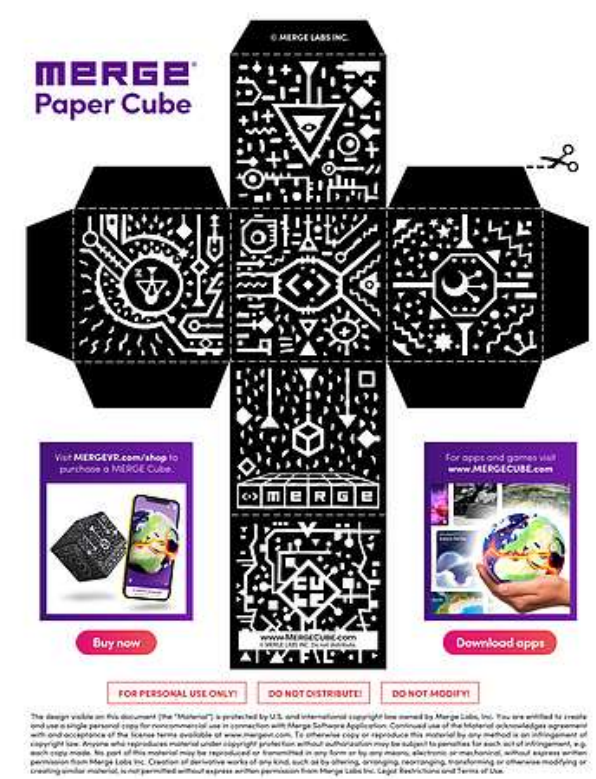

Fonte: Site ARVRinEDU, 2020.

Utilizando a Realidade Aumentada, como ponto de partida, e o aplicativo "Merge Explorer" na opção "Galactic Explorer", que projeta o Sistema Solar, trazemos o assunto para um diálogo com a Arte a partir do artista capixaba, de origem síria, Hilal Sami Hilal, bastante reconhecido no cenário artísticocultural, e de suas obras "Constelações" (Figura 3) e "Mira” (Figura 4).

Hilal Sami Hilal estudou Artes Plásticas na UFES e iniciou sua produção artística com pinturas em aquarelas, posteriormente, passou a fabricar papel artesanal, o que ocasionou duas viagens ao Japão a fim de aprimorar a sua técnica (HILAL, 2019).

Suas obras cruzam influências das culturas orientais e ocidentais, atravessando o moderno e o antigo (OÁ GALERIA ARTE CONTEMPORÂNEA, 2019), como podemos notar em sua obra "Constelações" (2016) e no objeto brinquedo "Mira" (2019), ambas escolhidas para fazerem parte do nosso projeto de pesquisa.

A obra coletiva, intitulada "Constelações" (2016), foi inspirada na pintura do artista holandês Vincent Van Gogh "Noite estrelada” de 1889, tendo a participação de 2.500 estudantes de escolas estaduais da Grande Vitória. $O$ trabalho foi produzido em papel artesanal de fibra de algodão colorido sobre tecido transparente, refletindo, por meio de espelhos colocados em toda a extensão do teto, as caligrafias que apresentam 10.000 nomes de pessoas que marcaram a vida dos estudantes, despertando memórias e o lado afetivo, além de questionar o nosso lugar no universo (ISSUU, 20I6).

\footnotetext{
${ }^{5}$ Disponível em: <https://www.arvrinedu.com/post/merge-cube-printable> Acesso em 29/04/202I. 
Figura 3: Constelações, 2016.

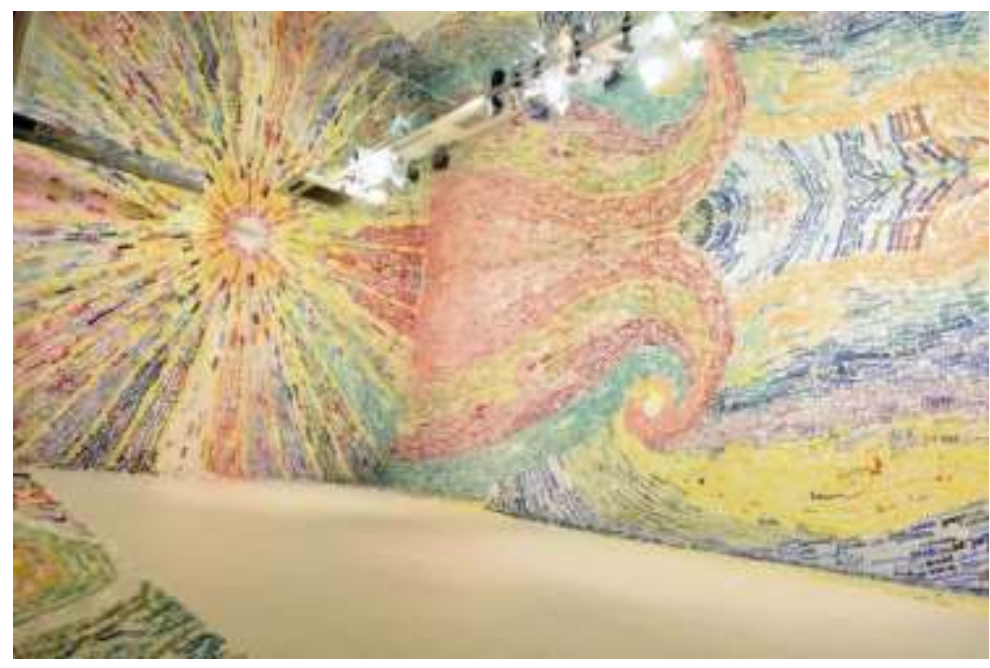

Fonte: Gazeta Online, $2020^{6}$

Em "Mira” (2019), temos uma casa de acrílico, que o artista denomina "universo". Local que preenchemos com memórias, afetos e vivências e, assim, repleto dessa carga emocional, tornou-se lar. "Mira" é um brinquedo construído por Hilal Sami e seu filho Ori Hilal para a exposição \#opequenocolecionador, que aconteceu em São Paulo, em 2019, na Carbono Galeria. A obra convidanos, a partir do desenho, a transformar o objeto artístico em algo afetivo como a nossa casa.

Figura 4: Mira, 2019

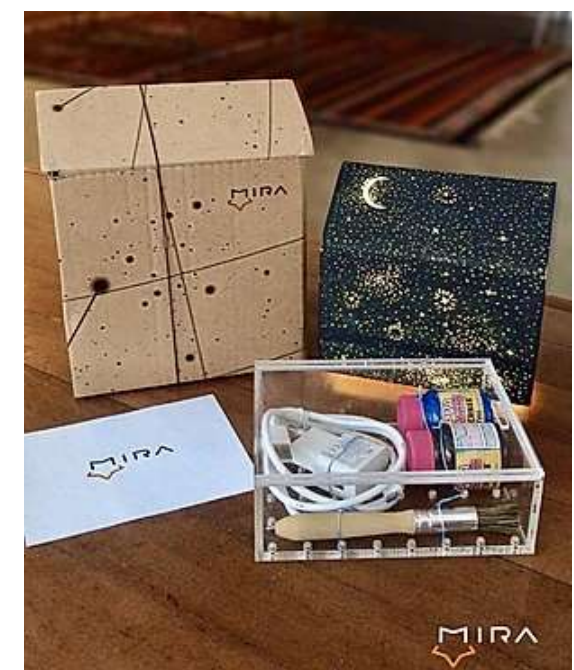

Fonte: Site O pequeno Colecionador, $2020^{7}$

\footnotetext{
${ }^{6}$ Disponível em: <https://www.gazetaonline.com.br/entretenimento/cultura/2016/08/exposicao-constelacoes-de-hilal-sami-hilal-aberta-a-partir-de-sexta-1013962398.html> Acesso em 29/04/202I.

${ }^{7}$ Disponível em: <https://www.opequenocolecionador.com.br/product-page/mira> Acesso em 29/04/202I.
} 
Com a finalidade de introduzir o assunto, sugerimos a exibição do vídeo "Show da Luna Via Láctea" (I I min40). Em seguida, reunimos as crianças em roda e conversamos sobre os elementos que existem na Via Láctea, ou seja, planetas, estrelas, luas, assim como outros elementos que o vídeo traz, e, também, sobre os meios tecnológicos utilizados para a observação deles. Além disso, falamos que existem estudiosos que estudam o céu: os astrônomos, os astronautas e a empresa NASA, mas que também existem artistas que se inspiram nesses elementos, que um deles foi o capixaba Hilal Sami Hilal e que as obras citadas retratam os elementos celestes.

Como parte de um desdobramento da atividade, propusemos que as crianças desenhassem estrelas, como o artista fez em suas obras. Depois pedimos que cada uma fixasse seu desenho num tecido preto, para compor o cenário da galáxia Via Láctea, que ficaria completo com o uso do Merge Cube.

Ao mostrar o Cubo, explicamos que aqueles desenhos que existem nele são códigos/letrinhas que somente $\circ$ celular consegue ler e que, assim que se colocasse $\circ$ aparelho diante do cubo, apareceriam os planetas e as luas. Pode-se pendurá-lo no painel/cenário para facilitar a interação com as crianças.

Também sugerimos, para o momento da interação, o uso do aplicativo Light Painting, que proporciona um registro fotográfico a partir de uma performance artística com luzes ou lanternas, a fim de dar mais realismo à cena.

\section{Considerações finais}

Visando realizar a análise comparativa das práticas das escolas de Vitória e de Vila Velha, inicialmente, fizemos a entrevista, a partir de um questionário, com pedagogos/as e professores/as. Nessas entrevistas, percebemos que a inserção das novas tecnologias acontece timidamente, tanto nos momentos regidos pela figura do dinamizador/a de Arte, quanto nos regidos pelos/as pedagogos/as, apesar de todas as entrevistadas concordarem que é uma prática atrativa para as crianças, considerando que elas já crescem inseridas na Cultura Digital e Tecnológica.

Nesse sentido, ao analisarmos as narrativas de uma professora, destacamos que ela coloca, como desafio, o fato de não haver Laboratórios de Informática na Educação Infantil e infere que, geralmente, vê poucas iniciativas de formação sobre o assunto. Entretanto, a partir da proposição que realizamos, inferimos que não necessariamente o laboratório de informática resolveria essa questão, pois entendemos que $\circ$ acesso das crianças às novas tecnologias pode ser viabilizado por outros recursos. O recurso do computador, apesar de ser interessante para as crianças, não é a única opção para a inserção tecnológica. Câmeras fotográficas, tablets e smartphones são tão potentes quanto, e ainda mais acessíveis para as crianças bem pequenas.

Olhar de professor, Ponta Grossa, v. 24, p. 1-20, e-17578.064, 2021.

Disponível em <https://revistas2.uepg.br/index.php/olhardeprofessor > 
Arte e cultura digital na Educação Infantil: a galáxia na palma da mão

Nessa perspectiva, desenvolvemos uma proposta de atividade para as crianças da Educação Infantil em que a Arte e a Tecnologia estão imbricadas. Por conseguinte, compreendemos que essa ação poderá contribuir para a formação de educadores/as da Educação Infantil dos CMEIS/UMEIS, pesquisadores, dentre outros, ou seja, os/as professores/as licenciados/as em Artes Visuais e em Pedagogia.

Salientamos, também nesta pesquisa, a importância de haver formações continuadas voltadas para essa temática, pois elas estão integrando agora os currículos das Universidades brasileiras, entretanto, a Geração Alpha já está nas escolas (Furtado, 2019). Nesse sentido, há uma lacuna na formação dos profissionais de educação já atuantes, propondo, para o ensino da Arte na/para a Educação Infantil, a produção de outros saberes-fazeres a partir do viés dialógico com a Arte Contemporânea relacionada com a Cultura Digital e que, ao nosso ver, configura-se como um excelente caminho para as crianças e professoras/es trilharem juntas/os.

\section{Referências}

ANDRION, R. Realidade aumentada: você sabe o que é?. [0I.07.20 I9] Olhar Digital. Disponível em: <https://olhardigital.com.br/noticia/realidade-aumentada-voce-sabe-o-que-e/87467> Acesso em $20 / 07 / 2020$

BAKHTIN, M. Estética da criação verbal. 4.ed. São Paulo: Martins Fontes, 2003.

BARBOSA, G. C.; BORGES, L. M.; FERREIRA, M. M. G. de A.; SANTOS, A. G. dos. Tecnologias Digitais: Possibilidades e desafios na educação infantil. ESUD 2014 - XI Congresso Brasileiro de Ensino Superior à Distância. UNIREDE. Florianópolis, 20I4. Disponível em: <http://esud20 I4.nute.ufsc.br/anais-esud20 I4/files/pdf/I28I52.pdf> Acesso em I2/08/2020.

BRASIL. Base Nacional Comum Curricular (BNCC, 2017). Disponível em: $<$ http://basenacionalcomum.mec.gov.br/download-da-bncc> Acesso em 08/05/2019.

BORGES, C. Cultura digital: quais são as suas características e influências na sociedade? [26.10.2019?] Rock Content. Disponível em: <https://rockcontent.com/br/blog/culturadigital/\#: :text=A\%20cultura\%20digital\%20pode\%20ser,tecnologias\%20de\%20informa\%C3\%A7\%C3\% A3०\%20e\%20comunica\%C3\%A7\%C3\%A3o.> Acesso em 17/08/2020.

CALLEGARO, T. Ensino da arte na Internet: contexto e pontuações. In: BARBOSA, A. M. (org.). Inquietações e mudanças no ensino da arte. São Paulo: Cortez, 2003.

EVANGELISTA, C. da S. O Ensino da Arte através do Computador: Uma Proposta de Prática Pedagógica para o Ensino Fundamental. V Colóquio Internacional: “Educação e Contemporaneidade", São Cristovão- SE/Brasil, p. I-16, setembro de 201 I.

FURTADO, C. C. Geração Alpha e a leitura literária: os aplicativos de literatura - serviços incentivam a prática? In: Revista Brasileira de Biblioteconomia e Documentação. v. I5, n. esp. Melhores trabalhos CBBD. Eixo II - IV Fórum de Biblioteconomia Escolar: pesquisa e práticas rumo ao desenvolvimento humano, 2019.

Olhar de professor, Ponta Grossa, v. 24, p. 1-20, e-17578.064, 2021.

Disponível em <https://revistas2.uepg.br/index.php/olhardeprofessor > 
HILAL S. H. In: ENCICLOPÉDIA Itaú Cultural de Arte e Cultura Brasileiras. São Paulo: Itaú Cultural, 2019. Disponível em: <http://enciclopedia.itaucultural.org.br/pessoa9856/hilal-sami-hilal> Acesso em: 01/08/2020.

ISSUU. Constelações: Hilal Sami Hilal. 2016. Disponível em:

<https://issuu.com/studiorb/docs/constelacoes> Acesso em: 0I/08/2020.

LE GOFF, J. História e memória. 4. ed. Campinas: UNICAMP, 1996.

LÉVY, P. Cibercultura. Trad. Carlos Irineu da Costa. São Paulo: Editora 34, 1999. Disponível em: $<$ https://mundonativodigital.files.wordpress.com/2016/03/cibercultura-pierre-levy.pdf> Acesso em $27 / 08 / 2020$.

LIBÂNEO, J. C. Adeus professor, adeus professora? novas exigências educacionais e profissão docente. 9. ed. São Paulo, Cortez, 2006. (Coleção: Questões da Nossa Época; v. 67).

LOUISE, V. Internet como suporte criativo. In: ARTSOUL. Arte Contemporânea. Publicado por ARTSOUL em abril 16, 2020. Disponível em: <https://blog.artsoul.com.br/arte-contemporaneainternet-como-suporte-criativo/> Acesso em 20/06/2020.

MULLER, J. C. Jogos e brincadeiras com o uso das tecnologias móveis na educação infantil: O QUE AS CRIANÇAS TÊM A NOS DIZER? 37 Reunião Nacional da ANPEd - 04 a 08 de outubro de 2015, UFSC - Florianópolis. Disponível em: <http://37reuniao.anped.org.br/wpcontent/uploads/2015/02/TrabalhoGT07-4367.pdf> Acesso em 12/08/2020.

PEREIRA, A. R, LOPES, R. de D. Legal: Ambiente de Autoria para Educação Infantil apoiada em Meios Eletrônicos Interativos. SP: 2005. In. BARBOSA, G. C.; BORGES, L. M.; FERREIRA, M. M. G.

Tecnologias Digitais: Possibilidades e Desafios na Educação Infantil. ESUD - XV Congresso de Ensino Superior a Distância. Florianópolis, 20I4. Disponível em: <http://esud20I4.nute.ufsc.br/anaisesud20 I4/files/pdf/I28I52.pdf> Acesso em I2/08/2020.

PIMENTEL, L. G. Tecnologias contemporâneas e o ensino da Arte. In: BARBOSA, Ana Mae (org.). Inquietações e mudanças no ensino da arte. São Paulo: Cortez, 2003.

PINTO, C. A. S; SILVA, A. C; ANJOS, A. M. As novas tecnologias na formação de professores: um relato de experiência. In: PINTO, C. A. S. (Org.). A produção do conhecimento no Curso de Educação Física: o desafio de formar professores pesquisadores. Recife: Imprima, 2017. p. 49-59.

PRETTO, N. de L.; PINTO, C. da C. (Orgs). Tecnologias e novas educações. In: Revista Brasileira de Educação v. II n. 31 jan./abr. 2006.

PRETTO, N. L., ASSIS, A. Ensaio: cultura digital e educação: redes já! In: PRETTO, NL., SILVEIRA, SA. (Orgs). Além das redes de colaboração: internet, diversidade cultural e tecnologias do poder. [online]. Salvador: EDUFBA, 2008. pp. 75-83. ISBN 978-85-2320-889-9. Available from SciELO Books $<$ http://books.scielo.org>.

REILY, L.. Escola Inclusiva: linguagem e mediação. Ed. Papirus, Campinas-SP, 2004.

SECRETARIA MUNICIPAL DE EDUCAÇÃO DE VITÓRIA. Diretrizes Curriculares da Educação Infantil Temas Infantis de Vitória TIV'S. Vitória, 2017.

Olhar de professor, Ponta Grossa, v. 24, p. 1-20, e-17578.064, 2021.

Disponível em <https://revistas2.uepg.br/index.php/olhardeprofessor> 
SILVA, da G.. Proposta Pedagógica Da Educação Infantil Caderno I - Orientação Curricular: A articulação dos saberes e experiências infantis. Gilmara da Silva (Org.). Vila Velha, 2012.

SOUZA, M. A. Metodologia da Pesquisa em Educação. Ponta Grossa: Ed. UEPG, 2009. 117p. il. Reimpressão 2014.

Recebido em: 08 de março de 202I.

Versão corrigida recebida em: 04 de maio de 2021.

Aceito em: 25 de maio de 2021 .

Publicado online em: 26 de junho de 2021 .

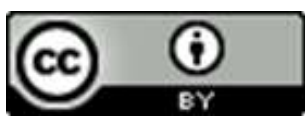

